\title{
Cálculo da Probabilidade e Quantificação do Volume de Material Suscetível a Escorregamentos - Bacia do Rio Jacareí, Morretes - PR
}

Calculation of the Probability and Quantification of the Volume of Material Susceptible to Slides Jacarei River Basin, Morretes - PR

\author{
RODRIGO MARQUES FOLADOR ${ }^{1}$, CLAUDINEI TABORDA SILVEIRA $^{1}$, ALBERTO PIO FIORI $^{1}$
}

${ }^{1}$ Universidade Federal do Paraná - UFPR, Paraná-rmfolador@gmail.com, claudineits@ufpr.br, fiori@ufpr.br

\begin{abstract}
Resumo
Em 2011, nos municípios de Morretes e Paranaguá, ocorreram grandes movimentos de massa, que foram estudados para entender os processos e, com isso, gerar produtos que auxiliem na prevenção de tais catástrofes. A Bacia do Rio Jacareí, área limítrofe entre estes municípios e uma das mais atingidas, foi o foco do estudo. Este trabalho aplica uma metodologia para quantificar o volume de material suscetível aos escorregamentos, através do cálculo da probabilidade de ocorrência destes escorregamentos. Para isso, foi gerado em ambiente SIG, um modelo digital de elevação e, a partir desse, foram realizados os processamentos dos atributos topográficos, utilizados para atribuir valores a um mapa de solos por meio de álgebra de mapas. Esse mapa representou espacialmente os locais com diferentes tipos de solos. Cada tipo apresenta características físicas também distintas, que foram adquiridas por meio de ensaios de cisalhamento direto e comparações com trabalhos anteriores. Esses diferentes parâmetros físicos determinados, foram aplicados no cálculo do Fator de Segurança, realizado em ferramenta SIG, na qual foi possível calcular equações aplicadas a grids espacializadas. Sendo assim, para o cálculo da probabilidade de escorregamentos, foi gerado o modelo espacializado do desvio padrão do Fator de Segurança. Da mesma forma, para representar o volume de solo desmoronado, foi gerado um modelo espacial através do cálculo da área da cunha instável de solo, multiplicada pelo comprimento linear da porção propensa ao desmoronamento, este estimado pelo modelo espacial da probabilidade. Como resultados, foi possível observar os principais focos de risco na área da bacia, nos relevos mais acidentados. Calculado o desvio padrão do Fator de Segurança, foram obtidos os valores do coeficiente de segurança e reclassificados com base em uma tabela de distribuição normal, resultando na probabilidade. Os valores mostraram áreas com alta probabilidade principalmente ao Sul da bacia. A partir dos valores encontrados, as áreas mais suscetíveis foram separadas por classes referentes às probabilidades determinadas e posteriormente utilizadas para o cálculo do volume de material suscetível a escorregamentos.
\end{abstract}

Palavras-chave: Probabilidade de escorregamentos; SIG; bacia do Jacareí; quantificação do volume.

\begin{abstract}
In 2011, in the municipalities of Morretes and Paranaguá, large mass movements occurred, which were studied to understand the processes and, with this, to generate products that help in the prevention of such catastrophes. The Jacarei River Basin, a border area between these municipalities and one of the most affected, was the focus of the study. This work applies a methodology to quantify the volume of material susceptible to landslides by calculating the probability of occurrence of these landslides. For this, a digital elevation model was generated in GIS environment, and from there, the topographic attributes were processed to assign values to a soil map through map algebra. This map spatially represented sites with different types of soils. Each type has also different physical characteristics, which were acquired through direct shear tests and comparisons with previous works. These different physical parameters were applied in the calculation of the Safety Factor, performed in a GIS tool, in which it was possible to calculate equations applied to spatialized grids. Thus, to calculate the probability of landslides, the spatial model of the standard deviation of the Safety Factor was generated. Similarly, to represent the volume of collapsed soil, a spatial model was generated by calculating the area of the unstable wedge of soil, multiplied by the linear length of the portion prone to collapse, estimated by the spatial model of probability. As a result, it was possible to observe the main foci of risk in the area of the basin, in the most rugged reliefs. Calculating the standard deviation of the Safety Factor, the safety coefficient values were obtained and reclassified based on a normal distribution table, resulting in probability. The values showed areas with high probability mainly to the south of the basin. From the values found, the most susceptible areas were separated by classes related to the determined probabilities and later used to calculate the volume of material susceptible to landslides.
\end{abstract}

Keywords: Probability of landslides; SIG; the Jacarei basin; quantification of volume. 


\section{Introdução}

No início de 2011, a Serra do Mar Paranaense ficou marcada por grandes movimentos de massa que alteraram uma extensa área nos municípios de Morretes e Paranaguá, devido à destruição provocada, atingindo comunidades que tiveram casas carregadas, pontes destruídas e moradores vindo a óbito. Nos anos seguintes grande parte da vegetação se recuperou rapidamente, porém ainda é possível ver as cicatrizes resultantes dos escorregamentos que marcaram a Serra da Prata e consequentemente a Bacia do Rio Jacareí.

Após o evento, a Minerais do Paraná (MINEROPAR), em parceria com a Universidade Federal do Paraná (UFPR) realizaram uma série de tentativas, como ensaios físicos e mapeamentos, englobados em projetos como o Geotecnia Litoral (UFPR), para entender os processos físicos responsáveis pela geração dos escorregamentos e gerar produtos que auxiliassem na prevenção de catástrofes, sendo essencial para a aquisição de informações, mapas e outros objetos que servem de base para trabalhos futuros. Porém, mesmo com a ampliação das informações a respeito da dinâmica dos movimentos de massa, ainda existe dificuldade em montar um sistema que seja efetivo na prevenção dos escorregamentos, principalmente por fazerem parte da dinâmica evolutiva de um sistema complexo como a Serra do Mar.

É importante, junto com a compreensão dos parâmetros que influenciam nos processos de movimentação, buscar um método para a prevenção desses eventos. Para isso é necessário testar novas técnicas e aperfeiçoar as existentes, sendo que por se tratar de um sistema natural da evolução do relevo, é difícil afirmar que se alcance uma técnica de prevenção completamente eficaz.

Atualmente, para a análise dos eventos de escorregamentos, aplicam-se técnicas com o apoio de ferramentas de Sistemas de Informações Geográficas (SIG) no tratamento dos dados, bem como para a geração de modelos utilizados como ferramentas de auxílio, além de mapas com informações sobre as áreas de suscetibilidade a movimentos de massa.

A dinâmica natural das áreas com maiores declividades e grandes elevações é a causa para a instabilidade das encostas e é algo que pode ser previsto. Com isso, há uma grande necessidade pelo aperfeiçoamento dos modelos e das técnicas existentes, na tentativa de minimizar todos os danos causados pelos movimentos de massa compreender os agentes causadores desses movimentos e utilizando novas técnicas mais eficazes para a prevenção, diminuindo o impacto sobre as comunidades que vivem nos locais atingidos.

Buscando esta compreensão, Tsutsui et al. (2007) utilizam Modelos Digitais de Elevação (MDE) para detectar movimentos de massa por diferença na elevação de dois destes modelos, gerados antes e depois do evento, estimando o volume com base nessa diferença. Após a obtenção da área dos escorregamentos, realizaram o cálculo da variação de profundidade para cada área, com base nas variações de declividade entre os MDE. Após adquirir a área delimitando as cicatrizes e profundidades, calcularam o volume.

Da mesma forma, Fiani, Fazio e Barberella (2000) fizeram comparações de antes e depois do evento de escorregamento ocorrido, para também gerar MDE e calcular o volume, utilizando algoritmos de interpolação e limites da área de interesse, para individualizar a variação morfológica do terreno. Com a análise dos modelos foi possível observar as zonas de erosão, correspondentes às áreas que são afetadas pelos escorregamentos. Os autores afirmam que para o cálculo do volume, como estão envolvidos os algoritmos de interpolação e as condições de limite da área de interesse, se mantiver fixo o interpolador, o volume varia com a definição altimétrica do limite (boundary effect). Uma vez que o algoritmo esteja definido, junto com os intervalos das curvas de nível, o mesmo deve ser utilizado para todos os MDE, sendo possível adquirir os volumes.

Ambos os trabalhos citados apresentam formas de calcular o volume de material movimentado, em uma área já afetada por movimentos de massa, pois são necessárias informações pretéritas da superfície que escorregou para utilizar de comparação com a superfície pós evento.

Diferente das técnicas citadas, o objetivo principal do trabalho é aplicar o método de quantificação do volume de material suscetível a escorregamentos proposto por Fiori \& Carmignani (2009), em um SIG (Sistemas de Informações Geográficas), gerando modelos que representem espacialmente as áreas com maior probabilidade de movimentação -.

São vários os fatores que condicionam os movimentos e, por isso, é difícil afirmar quando e onde irão ocorrer. Portanto, a área contemplada pela pesquisa é a bacia do Jacareí, situada nos municípios de Morretes e Paranaguá, na Serra do Mar Paranaense (Figura 1), como forma de aproveitar a oportunidade de estudar um local já atingido pelos escorregamentos, apesar do acesso ser acidentado, possuindo áreas com mais de $45^{\circ}$ de inclinação.

\section{Materiais e Métodos}

Para a quantificação do volume de material suscetível aos escorregamentos é necessário, antes de mais nada, realizar a modelagem do Fator de Segurança das encostas e em seguida, trabalhar como um modelo de probabilidade de escorregamentos.

O método baseia-se na utilização dos dados resultantes do Fator de Segurança para o cálculo da probabilidade e posterior quantificação do volume. Para isso, parte-se da determinação dos parâmetros de coesão, ângulo de atrito, peso específico natural, inclinação da encosta e espessura do solo, como forças resistentes e cisalhantes. 


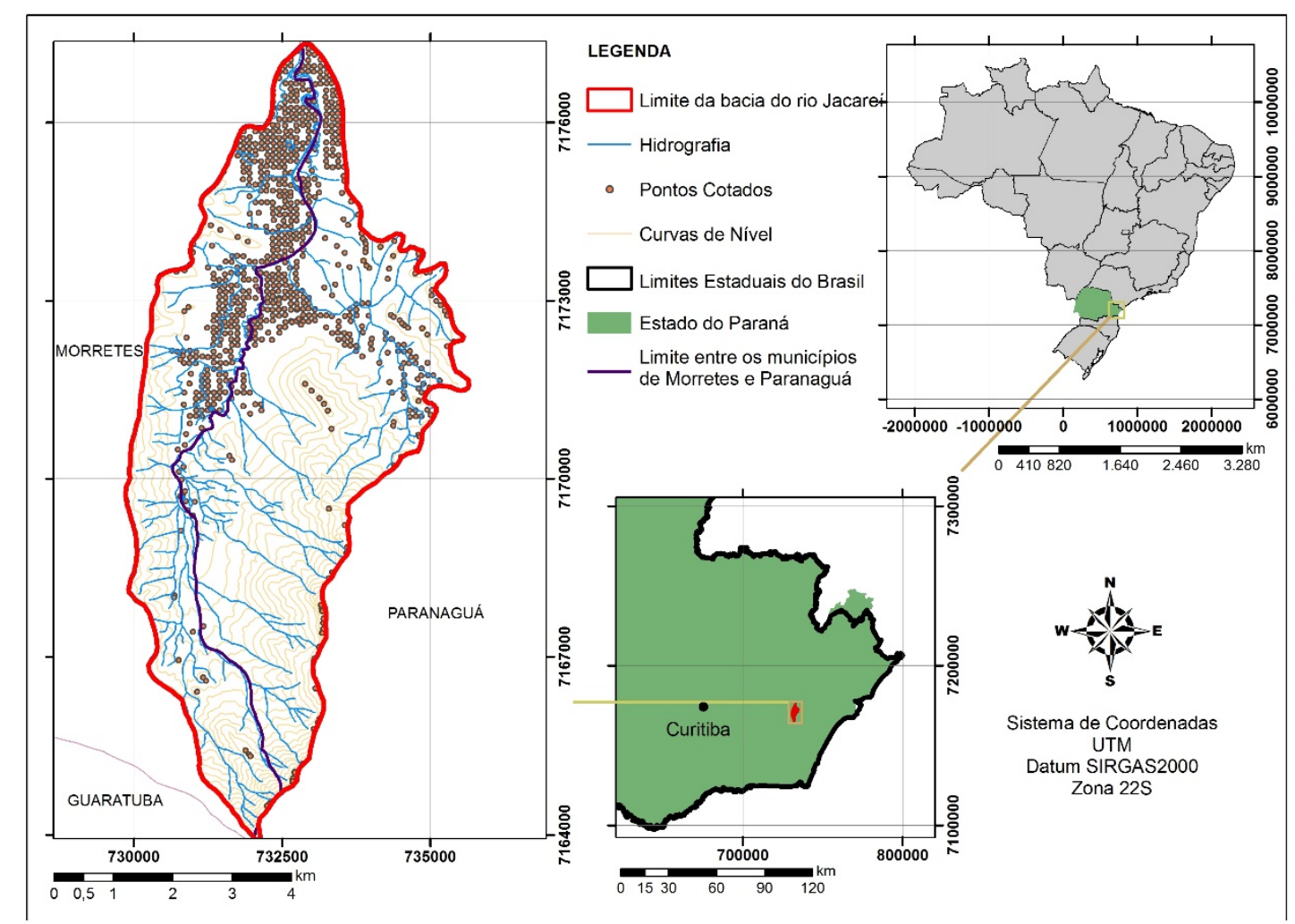

Figura 1 - Área contemplada pela pesquisa, delimitada com base na Bacia Hidrográfica do Rio Jacareí, Serra do Mar Paranaense.

\subsection{Organização do Banco de Dados}

Para a delimitação das cicatrizes dos escorregamentos, bem como das extensões e os trajetos do material que desprendeu, foi utilizada imagem de satélite de alta resolução (WorldView). As bases vetoriais planialtimétricas foram adquiridas através de levantamento aerofotogramétrico, realizado pela MINEROPAR na escala 1:10.000, com intervalos de 5 metros entre as curvas, o que possibilitou a geração de um Modelo Digital de Elevação (MDE) bastante detalhado, com 5 metros de resolução espacial.

A partir do MDE, foram realizados os processamentos dos seguintes atributos topográficos: declividade, plano de curvatura e índice topográfico de umidade (ITU), que foram utilizados para atribuir valores ao mapa de solos, por meio da álgebra de mapas (DECLIV. + PC + ITU + HIPSOMETRIA = TIPO DE SOLO). As classes de solos estabelecidas para os valores encontrados foram baseadas no trabalho de Silveira (2010), e também na classificação do EMBRAPA (2006), de forma que fosse mais fácil distinguir os tipos de solos pertencentes às determinadas classes. A declividade e o plano de curvatura foram processados diretamente sobre o MDE em ferramentas do Software ArcGis ${ }^{\circledR}$, já o ITU (w) foi calculado utilizando a razão entre a Área de Contribuição (Ac) e a tangente da declividade $(\beta)$, conforme modelo apresentado primeiramente por Beven \& Kirkby (1979), sugerindo que o escoamento está condicionado principalmente à declividade e dessa

\subsection{Modelagem dos Atributos Topográficos}

Para determinar os parâmetros físicos utilizados no cálculo da modelagem do Fator de Segurança (coesão, ângulo de atrito, peso específico), foi utilizada metodologia proposta por Silveira et al. (2012), que determinam estes parâmetros através da classificação dos diferentes tipos de solos e estes por sua vez, são classificados através do processamento e álgebra de mapas dos atributos topográficos.

forma está sujeito à restrição $0^{\circ}<\beta<90^{\circ}$. O parâmetro é calculado através da Equação 1:

$$
w=\ln (A c / \tan \beta) \quad \text { (Equação 1) }
$$

Quando a declividade é próxima de $0^{\circ}$, o limite tende ao infinito e quando é próximo de $90^{\circ}$, tende a 0 , ou seja, quanto mais plano o relevo, maior é a umidade.

A equação foi aplicada na ferramenta Raster Calculator contida no Software ArcGis ${ }^{\circledR}$, de forma que o programa pudesse utilizar os modelos raster da área de contribuição e declividade como as variáveis e, assim, atribuir valores para cada célula (Equação 2).

$w=I n(($ flow_accumulation_raster $) /$ tan(declividade_raster $))$

Equação (2)

A área de contribuição foi determinada através da geração de um modelo de acumulação de fluxo (rotina Flow Accumulation do software ArcGis ${ }^{\circledR}$ ). 
As variáveis declividade, plano de curvatura, índice topográfico de umidade e hipsometria, foram utilizadas para classificar os tipos de solos existentes na área da bacia. Para isso, essas quatro variáveis geomorfométricas foram cruzadas e cada uma foi dividida em classes, sendo que para representar cada classe, foi atribuído um valor numérico.
O objetivo foi tabular esses valores que representam cada classe, de forma que a soma seja um valor representativo das quatro variáveis, cada uma de seu respectivo modelo, para que esse valor final representasse um determinado tipo de solo, de acordo com os quatro parâmetros (Figura 2).

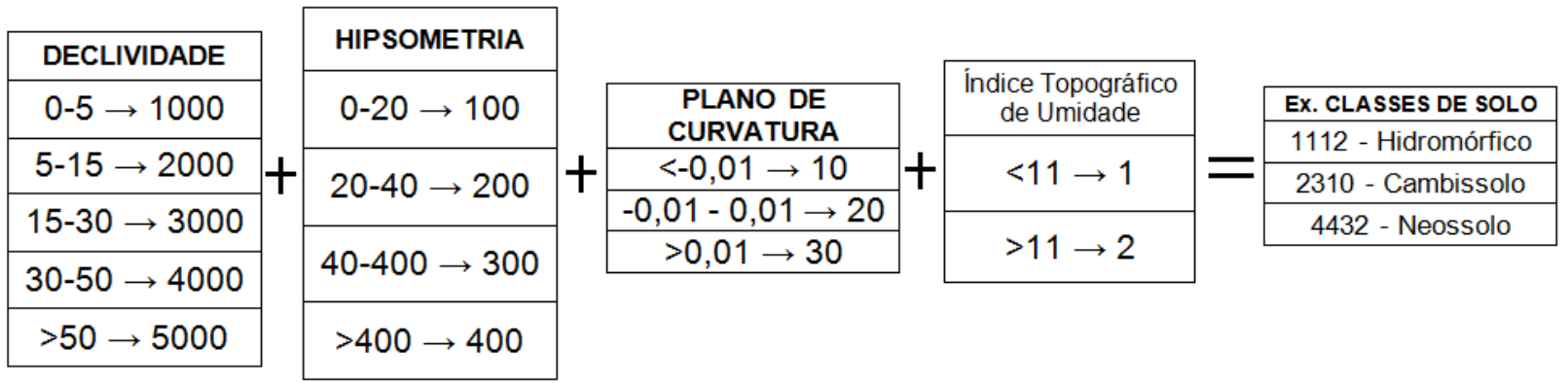

Figura 2 - Exemplo de caracterização do tipo de solo, a partir da modelagem digital do relevo.

Com o cruzamento dos parâmetros através da álgebra de mapas, foi possível separar 11 classes de solos com características físicas distintas. Porém, com a validação em campo, estas 11 classes tiveram que ser simplificadas, de modo que o modelo representasse apenas o que pôde ser observado no campo. Com isso, os 3 tipos de cambissolos distintos determinados, foram considerados como sendo apenas um tipo geral de cambissolo; os 2 tipos distintos de neossolos, se transformaram em um tipo geral de neossolo e assim por diante, até que o modelo com 11 classes fosse simplificado para 5 classes de solo distintas, constituídas por Solos Hidromórficos, Argissolos, Cambissolos, Associações de Cambissolos e Neossolos e por último Associações de Neossolos com Afloramentos.

\subsection{Modelagem do Fator de Segurança}

Para o cálculo do Fator de Segurança, foi utilizado método do equilíbrio limite, descrito em Fiori \& Carmignani (2009), no qual são levados em consideração a coesão do solo, peso específico, espessura da camada, saturação do solo, inclinação da vertente, o peso específico da água e a influência da vegetação.

Silveira et al. (2012) apresenta a análise do Fator de Segurança para a mesma bacia, utilizando a teoria do equilíbrio limite, além de utilizar o SIG como ferramenta para a modelagem e espacialização dos atributos necessários. Durante o trabalho foi realizada uma nova modelagem empregando a análise do Fator de Segurança a partir de uma base atualizada e com melhor resolução, conforme novas observações de campo, através da Equação 3 apresentada por Fiori \& Carmignani (2009).

$$
F s=\frac{c S+\left[\left(\gamma_{\text {nat }}-\frac{h_{w}}{h} \gamma_{a}\right) h \operatorname{cosi}+\sigma_{a} \operatorname{cosi}\right] \tan \varphi}{\left(h \gamma_{\text {nat }}+\sigma_{a}\right) \operatorname{sini}+\sigma_{v e}}
$$

Esta modelagem emprega valores das forças resistentes e mobilizantes, e mostra que existe uma variância associada a elas. Devido a essa variância, a probabilidade é calculada através do desvio padrão do Fator de Segurança.

Para determinar os parâmetros físicos utilizados para a modelagem do Fator de Segurança, foram realizados ensaios de cisalhamento direto, para determinar a resistência ao corte de um corpo de prova de solo de pequena espessura, representando uma situação real. Mede-se a resistência horizontal, em função da deformação vertical, em uma amostra colocada em uma célula de cisalhamento. O objetivo é, por meio da interpretação de uma envoltória linear, extrair os valores de ângulo de atrito interno do solo e do intercepto coesivo.

Os resultados dos ensaios foram comparados com os valores apresentados no trabalho de Kozciak (2005) que utilizou a mesma técnica para a bacia do Marumbi, também na Serra do Mar Paranaense. Além de determinar os parâmetros físicos, também determinou a variação de espessura dos horizontes de solo. Devido às semelhanças nas características físicas, os valores determinados pela autora foram validados com os ensaios de cisalhamento direto e extrapolados para a área do Jacareí, para calcular o Fator de Segurança com base no mapa de solos gerado. Os valores utilizados são apresentados na Tabela 1 .

A Espessura dos horizontes de solo segue basicamente o manual de solos do EMBRAPA (2006), com algumas alterações observadas em campo. 
Tabela 1 - Comparação dos índices físicos de solo das bacias do Marumbi e do Jacareí.

\begin{tabular}{|c|c|c|c|}
\hline Classes de solos & Índices físicos & Valores KOZCIAK (2005) & Ensaios \\
\hline \multirow{2}{*}{ Cambissolos } & Coesão(c) & $14,8 \mathrm{kN} / \mathrm{m}^{2}$ & $14 \mathrm{kN} / \mathrm{m}^{2}$ \\
\hline & Ângulo de Atrito $(\phi)$ & $23,2^{\circ}$ & $23,3^{\circ}$ \\
\hline \multirow{2}{*}{ Assoc. Cambissolos e Neossolos } & Coesão(c) & $17 \mathrm{kN} / \mathrm{m}^{2}$ & $17 \mathrm{kN} / \mathrm{m}^{2}$ \\
\hline & Ângulo de Atrito $(\phi)$ & $23,5^{\circ}$ & $20,5^{\circ}$ \\
\hline
\end{tabular}

Através da reclassificação do mapa com as cinco classes de solos, foram gerados modelos espaciais para cada parâmetro físico dos solos, entre eles a coesão, ângulo de atrito, declividade, espessura e peso específico, que após terem seus valores transformados em float, foram utilizados para realizar a álgebra de mapas através da ferramenta Raster Calculator, para resultar no modelo espacial do Fator de Segurança.

Os parâmetros referentes à influência da vegetação e do vento, utilizados na fórmula (3), foram extraídos da bibliografia, com base nas características da região da Serra do Mar. Para a influência do vento foi utilizado o valor da ordem de 1,0 kPa (Fendrich \& Ferreira, 1995) e para a influência das raízes, $5,0 \mathrm{kPa}(\mathrm{Wu}, \mathrm{McKinnell}$ e Swanston, 1979).

O valor que representa a saturação do solo (hw/h) foi fixado em 1, representando a pior condição que seria de $100 \%$ de saturação.

\subsection{Modelagem Digital da Probabilidade de Escorregamentos}

O cálculo da probabilidade a partir da análise do Fator de Segurança (FS) baseia-se no seguinte método:

a) É aplicada a teoria do Equilíbrio-limite, onde exercem influência nos valores determinísticos das forças resistentes e mobilizantes;

b) A estimativa destas forças mostra que há uma variância associada a elas. Com isso, para condições desfavoráveis, a ruptura pode ocorrer mesmo que o FS seja maior que a unidade;

c) Se definida uma margem de segurança (Ms) como: $\mathrm{Ms}=(\mathrm{R}-\mathrm{M})$, sendo " $\mathrm{R}$ " as forças resistentes e " $\mathrm{M}$ " as forças mobilizantes, esta margem de segurança terá uma variação aleatória e uma distribuição de probabilidade, nesse caso, $\mathrm{Pr}=\mathrm{P}(\mathrm{Ms}<0)$, ou seja, a probabilidade da margem de segurança ser inferior a 0 , como é mostrado a seguir (Figura 3).

d) A medida adequada dessa distribuição é dada pelo número de desvios padrão da média de Ms para a ruptura, expresso como Zc (coeficiente de segurança);

e) O FS também é função de um número de variáveis aleatórias, então considera-se que a distribuição de probabilidade do Fator de Segurança aproxima-se de uma distribuição normal;

Nesse caso, a distribuição de probabilidade do FS e da Ms será similar.

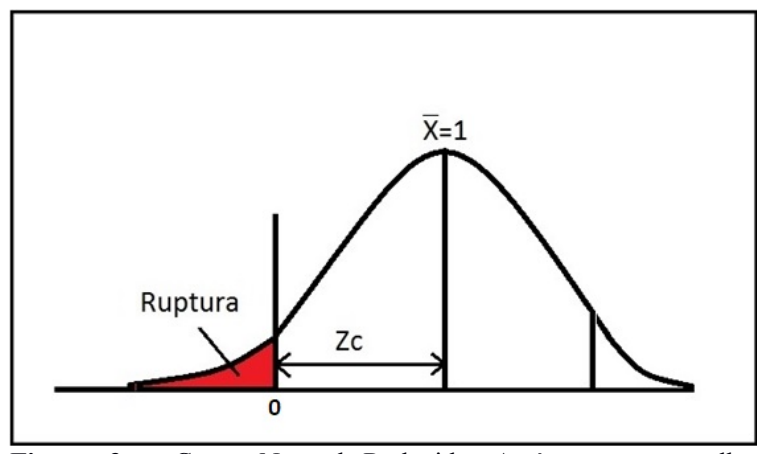

Figura 3 - Curva Normal Reduzida. A área em vermelho representa a probabilidade de que a margem de segurança seja menor do que 0 , em condições de ruptura.

O coeficiente de segurança pode ser determinado pela Equação 4:

$$
Z c=(F S-1) / \sigma F S \quad(\text { Equação } 4)
$$

A fórmula representada na Equação 4, adaptada para o Fator de Segurança é baseada no método estatístico para o cálculo da variável "Z", apresentada por Spiegel (1977).

O Modelo Espacial que representa os valores de Zc é gerado aplicando-se a Equação 4 na ferramenta Raster Calculator. Tendo o modelo especial, para determinar a probabilidade aplica-se o valor de cada célula em uma tabela de distribuição normal, que representa a área subentendida pela curva normal reduzida, equivalente ao valor de Zc (Spiegel, 1977). Essa área, subtraída da área total da curva, representa a probabilidade de escorregamento (Fiori \& Carmignani, 2009).

Para compreender melhor o modelo do coeficiente de segurança, as ideias foram divididas da seguinte forma:

a) A probabilidade é dada pelo valor da área da curva normal que se encontra à esquerda da abcissa, ou seja, abaixo do zero da ordenada, representada na Figura 3;

b) $\mathrm{O} Z \mathrm{z}$ é representado pela área entre a média da curva normal $(\mathrm{X})$ e o zero. O valor é determinado através da tabela de distribuição normal (Tabela 2);

c) Juntas, as áreas equivalem a $50 \%$ da área total representada pela curva.

Para calcular a probabilidade subtrai-se o valor de Zc determinado na tabela de distribuição, de $50 \%$ da área total.

Como trata-se de uma modelagem com base no Fator de Segurança, a média utilizada para a curva normal foi 
igual a um, sendo que valores maiores representam encostas estáveis e valores abaixo representam as encostas suscetíveis a escorregamentos.

Tabela 2 - Probabilidade determinada com base nos valores de Zc aplicados à tabela de distribuição normal.

\begin{tabular}{ccc}
\hline Probabilidade & $\begin{array}{c}\text { Área subentendida pela } \\
\text { curva normal reduzida }\end{array}$ & Zc \\
\hline $50 \%$ & $0-0,0250$ & $0-0,06$ \\
\hline $45 \%$ & $0,0250-0,0714$ & $0,07-0,18$ \\
\hline $40 \%$ & $0,0754-0,1217$ & $0,19-0,31$ \\
\hline $35 \%$ & $0,1255-0,1736$ & $0,32-0,45$ \\
\hline $30 \%$ & $0,1772-0,2224$ & $0,46-0,59$ \\
\hline $25 \%$ & $0,2258-0,2734$ & $0,60-0,75$ \\
\hline $20 \%$ & $0,2764-0,3238$ & $0,76-0,93$ \\
\hline $15 \%$ & $0,3264-0,3749$ & $0,94-1,15$ \\
\hline $10 \%$ & $0,3770-0,4236$ & $1,16-1,43$ \\
\hline $5 \%$ & $0,4251-0,4750$ & $1,44-1,96$ \\
\hline $0 \%$ & $0,4756-$ Máx. & $1,97-$ Máx. \\
\hline
\end{tabular}

\subsection{Quantificação do Volume}

O modelo especial do volume de material suscetível a escorregamentos foi calculado a partir dos valores determinados no modelo espacial de probabilidade, através da variância do Fator de Segurança.

$\mathrm{O}$ volume de solo desmoronado $(\mathrm{Vd})$ será dado pelo produto da área da cunha instável de solo (Ac), pelo comprimento linear do sulco propenso ao desmoronamento (Ac), estimado pela probabilidade (Pr), como mostra a Equação 5 (Fiori \& Carmignani, 2009).

$$
V d=A c \times D \times P r \quad \text { (Equação 5) }
$$

O cálculo do volume foi realizado através do modelo preditivo, ou seja, não foram levadas em consideração somente as áreas dos escorregamentos anteriores e sim todas as cunhas da bacia, que foram delimitadas por valores iguais de probabilidade.

A área foi determinada da seguinte forma: primeiro foram formadas cunhas de escorregamentos de acordo com células de iguais valores de probabilidade. Sabendo que cada célula possui $25 \mathrm{~m}^{2}$ de área, foram multiplicadas a quantidade de células de cada cunha por $25 \mathrm{~m}^{2}$.

Tendo a área de cada cunha, foi calculado o comprimento linear em cada uma e para isso, foram traçadas retas que vão do topo até a base da cunha, acompanhando a direção de fluxo. $O$ produto do comprimento da reta, com a área calculada e com a probabilidade, resulta no volume de material suscetível a escorregamentos.

\section{Resultados e discussões}

A possibilidade de geração de um MDE com resolução de $5 \mathrm{~m}$, permitiu bons resultados de visualização, inclusive com a correção do sentido de fluxo da hidrografia, que através da ferramenta TopoToRaster, além da elevação, representou corretamente os sulcos e córregos. O relevo gerado apresentou suavidade nos contornos em sua totalidade, sem traços falhos e imperfeitos. Esses bons resultados possibilitam maior acurácia nos modelos gerados a partir do MDE. Contudo, ao mesmo tempo que apresentou melhor discriminação nos detalhes, o modelo atribuiu feições inexistentes entre os intervalos de elevações quando validado em campo e com isso, a opção foi utilizar modelo gerado da mesma forma, porém com resolução de 15 metros, que se mostrou mais próximo da realidade.

A análise do plano de curvatura permitiu avaliar a distribuição do solo de acordo com a quantidade de água distribuída ao longo da vertente, conciliando os processos pedológicos com os hidrológicos. $\mathrm{O}$ modelo de declividade permitiu distinguir a grande e abrupta variação do relevo e como consequência, a variação nos tipos de solos caracterizados, bem como a espessura média baseada no acúmulo de sedimentos. Verifica-se baixa declividade próximo da área mais plana, gerando maior acúmulo de sedimentos; já os topos de morros mais íngremes, chegaram a apresentar até $70^{\circ}$ de inclinação e consequentemente solos mais rasos, por não gerar tanto acúmulo.

A análise do ITU permitiu caracterizar as áreas com maior acúmulo de umidade, que de acordo com o mapa equivalem às áreas com maior acúmulo de sedimentos e como consequência, maior espessura na camada de solo. Essa área representa as planícies da bacia do rio Jacareí, que receberam todo o material movimentado. Com isso foi possível observar que a maior parte da área, na qual ocorreram as movimentações, não caracteriza elevada saturação, mas que recebeu fortes chuvas e elevada erosão superficial. Os pontos que apresentam altas declividades e elevado índice de umidade, são áreas nas quais houve tempo para o solo absorver parte da água superficial. Na Figura 4 está o resultado da espacialização dos modelos de relevo, bem como as reclassificações dos intervalos de classes, necessários para gerar o mapa de solos. 

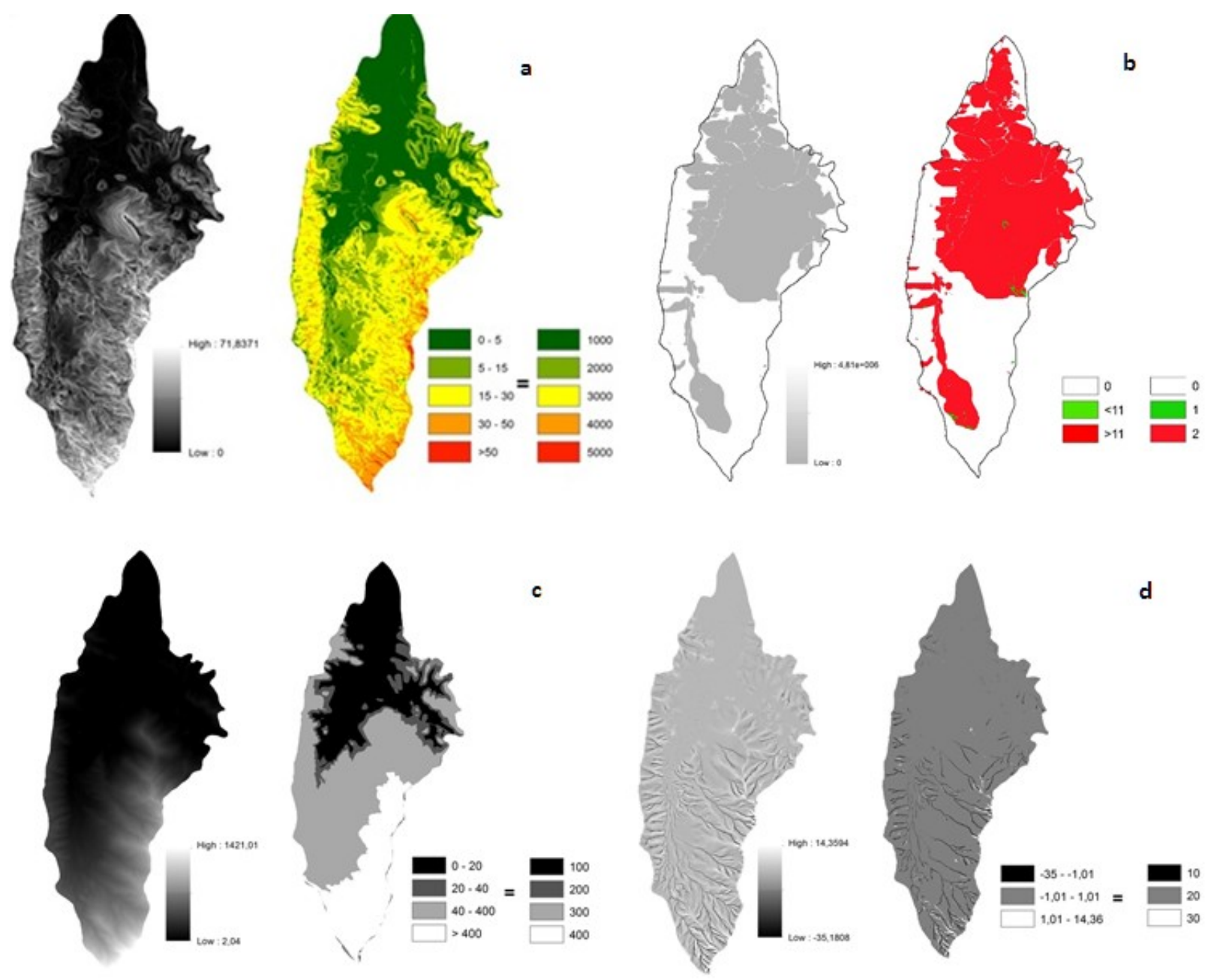

Figura 4 - Modelos de relevo. À esquerda na legenda, os intervalos de classe e à direita, as reclassificações para gerar o mapa de solos. a- Classes de declividade; b- Classes de ITU; c- Classes de hipsometria; d- Classes de plano de Curvatura.

Utilizando a álgebra de mapas, os modelos de declividade, ITU, hipsometria e plano de curvatura foram cruzados, constituindo modelo espacial com 11 classes de solo. Com a validação em campo, o mesmo foi simplificado de modo a representar 5 classes observadas.

Esta redução pode ser explicada pela dificuldade de acesso em muitas áreas na bacia do rio Jacareí, o que significa que não foram observados alguns horizontes de solos, porém não significa que não existam ou não possam ser classificadas de acordo com o modelo.

É possível observar a maior porcentagem de Associações de Cambissolos e Neossolos, totalizando $41,29 \%$ da área, além de 17,43\% de Cambissolos, $12,45 \%$ apenas de Argissolos, que foram considerados uma área de transição dos Cambissolos para os solos de caráter hidromórfico, 3,16\% de uma associação de Neossolos com Afloramentos Rochosos, na parte mais elevada e declivosa da bacia e um quarto correspondente à formação de Solos Hidromórficos, na porção mais plana, totalizando $25,67 \%$ (Figura 5)

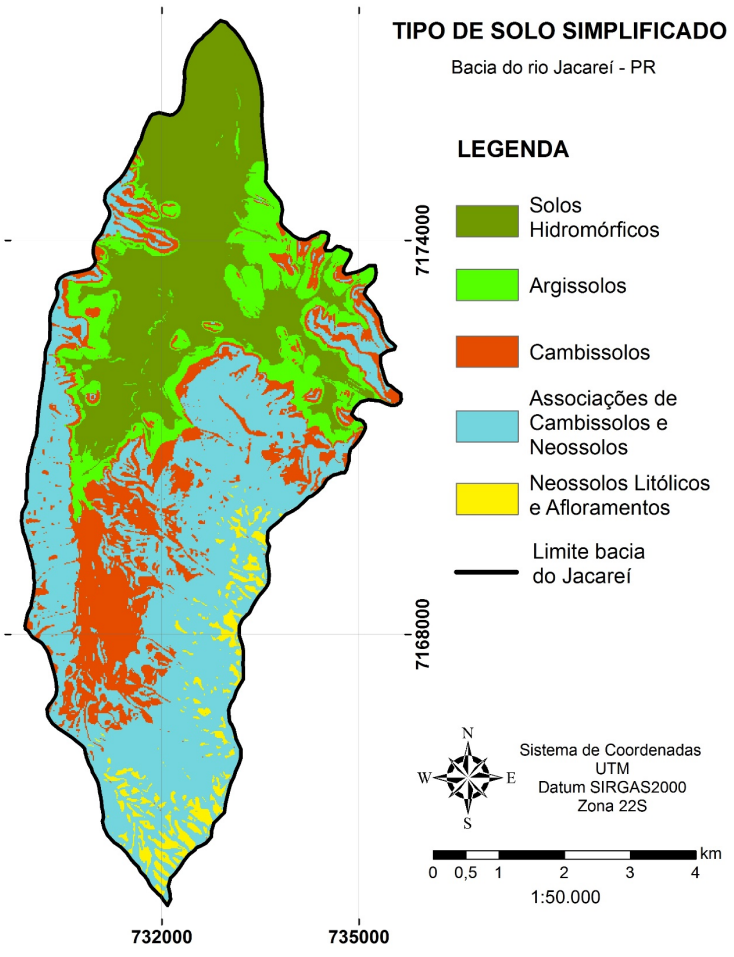

Figura 5 - Mapa de solos definido com as cinco classes observadas em campo. 
A partir do mapa de solos, foram gerados os modelos por reclassificação, dos parâmetros envolvidos na modelagem do Fator de Segurança (Figura 6).

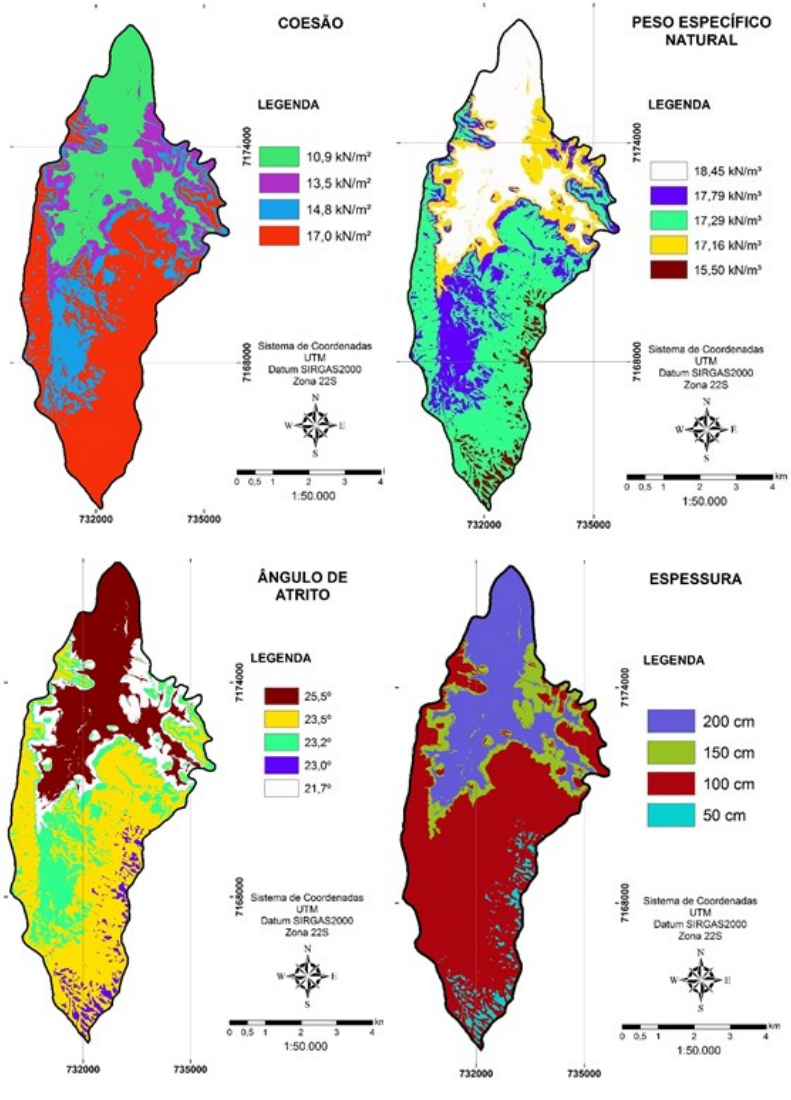

Figura 6 - Modelos espaciais dos parâmetros físicos referentes às classes de solos da bacia do rio Jacareí.

Os ensaios de cisalhamento direto provaram que os valores determinados por Kozciak (2005) são semelhantes ao encontrados na bacia do Rio Jacareí. Para os horizontes de Cambissolos, ambos os parâmetros coesão e ângulo de atrito resultaram em diferenças mínimas, de $0,8 \mathrm{kN} / \mathrm{m}^{2}$ e $0,1^{\circ}$, respectivamente.

Para as associações de Cambissolos com Neossolos, a coesão é a mesma em ambas as bacias, e o ângulo de atrito apresentou uma variação de $3^{\circ}$.

Com a semelhança física dos horizontes amostrados, os outros solos - Hidromórficos, Argissolos e Neossolos com Afloramentos - tiveram os valores mantidos, extrapolados da bacia do rio Marumbi.

\subsection{Mapa do Fator de Segurança}

Completados todos os modelos espaciais referentes aos parâmetros físicos dos solos e realizada a modelagem, foi montado um mapa do Fator de Segurança da bacia hidrográfica do rio Jacareí, apresentado na Figura 7. É possível observar que as áreas constituídas basicamente por relevo plano não apresentam FS baixos. A razão disso está no fato de que são áreas sem riscos de escorregamentos, pois não apresentam declividades altas, nem ângulos de atrito elevados. As áreas de planícies recebem todo o aporte de sedimentos que são transportados das regiões mais íngremes.

Já áreas com uma variação maior na elevação, no ângulo de inclinação das vertentes, resultam em um relevo mais acidentado, apresentando muitos focos de suscetibilidade, o que é observado principalmente nas áreas a Sul e Sudeste da bacia, que foram as mais atingidas no evento de 11 de março de 2011.

Essas áreas a Sudeste são as porções mais acidentadas da bacia, que tem variações maiores nos ângulos de atrito e na elevação, chegando até 1400 metros de altitude. Os topos dessas elevações apresentam muitos afloramentos graníticos, sem horizontes de solos, porém estão em contato com muitas associações de Neossolos com afloramentos.

Além das porções a Sudeste, as áreas a oeste também apresentaram vertentes com Fator de Segurança entre 1 e 1,5, em grande parte próximas às áreas de fluxo divergente. A quantidade é significamente menor, se comparadas com a porção Sudeste, pois apresentam menor declividade.

A porção central da bacia apresentou em grande parte Fator de Segurança maior do que 2,0, porque é a região de planície, com baixa coesão e baixo ângulo de atrito, que apresenta maiores espessuras por serem planícies de inundação.

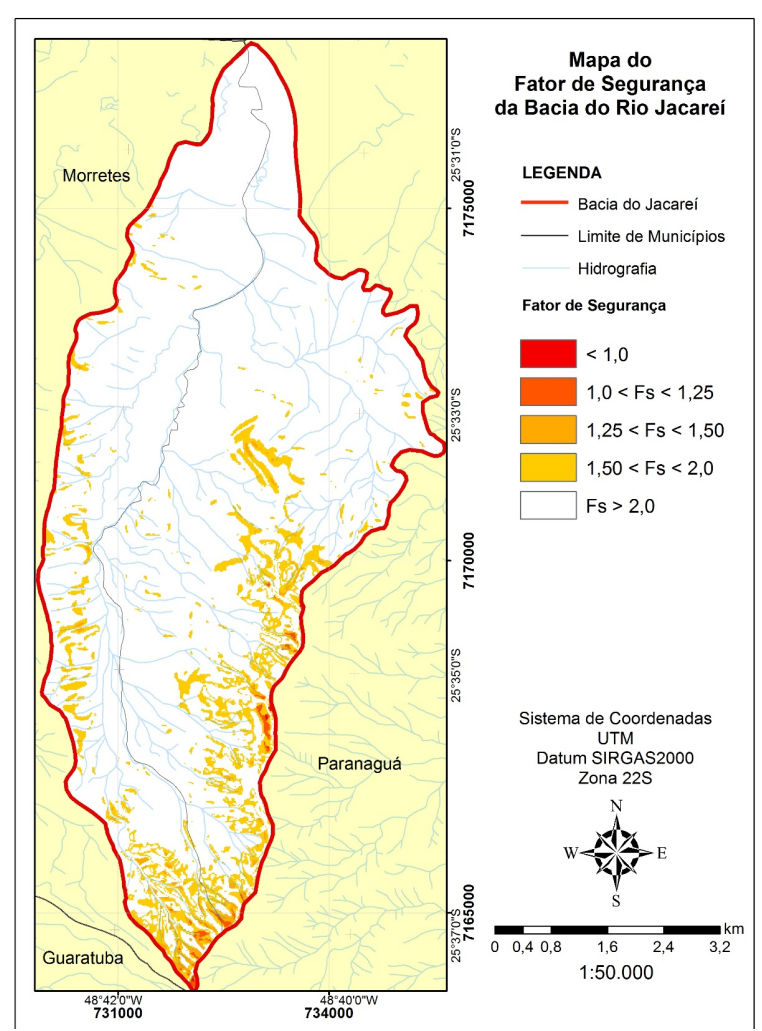

Figura 7 - Modelo espacial do Fator de Segurança da bacia do Rio Jacareí.

O Fator de Segurança considerado crítico está representado por valores abaixo de 1, porém comparado com as cicatrizes dos escorregamentos ocorridos, observa-se que muitas porções com valores 
entre 1 e 1,5 também sofreram movimentação. Nesse caso, o que pode distinguir a questão da movimentação ou de sua ausência, é o mapa de probabilidade, que pode representar estas áreas com probabilidades baixas, porém diferentes de 0 .

\subsection{Cálculo da Probabilidade}

Através da fórmula de Spiegel apresentada da Equação 4, foi gerado o modelo espacial de Zc, utilizando os valores determinados no modelo espacial do FS como variáveis. Esse modelo de Zc reclassificado com base na tabela de distribuição normal de Spiegel (1977) resultou no modelo espacial de probabilidade de escorregamentos, apresentado na Figura 8.

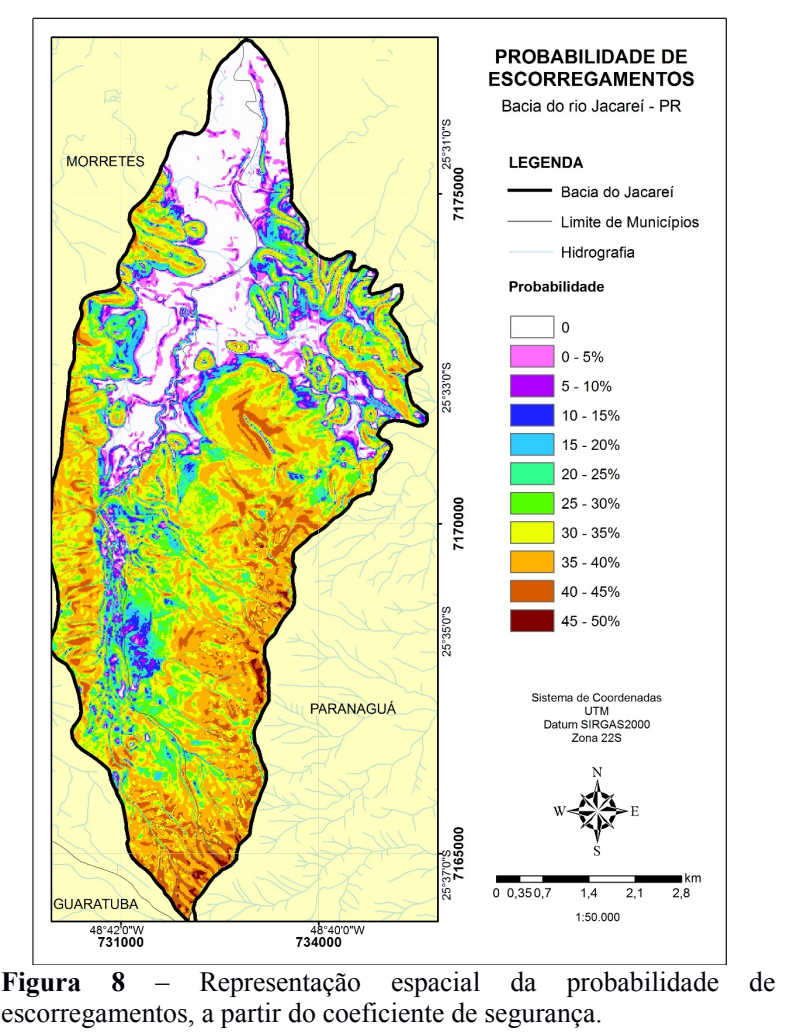

Para ser representado espacialmente, o modelo de probabilidade foi dividido em intervalos de classes de $10 \mathrm{em} \mathrm{10 \%}$. Estas foram então sobrepostas pelas áreas das cicatrizes do evento de 11 de março, e com isso foram gerados mapas da intersecção entre as respectivas classes e as cicatrizes. Esta análise permitiu determinar a quantidade de cicatrizes que estão sobrepondo o intervalo de probabilidade definido, para o total, a partir da metodologia utilizada.

O resultado foram $99,7 \%$ das cicatrizes com um valor de probabilidade diferente de 0. Destes, 99,6\% apresentaram probabilidade maior do que $10 \%$, $99,42 \%$, são probabilidades maiores que $20 \%, 97 \%$ maiores do que $30 \%$ e $74 \%$ maiores do que $40 \%$. Apenas $0,3 \%$ das cicatrizes encontram-se em área de probabilidade igual a $50 \%$, de acordo com o mapa.
O modelo mostrou que a maior quantidade das cunhas dos escorregamentos não se encontram nas áreas com maior probabilidade e sim nas áreas com probabilidades próximas de $30 \%$, em uma escala de 0 a $50 \%$. Este fato pode ser explicado devido a muitas áreas com probabilidades próximas a 50\% caracterizarem áreas de afloramentos rochosos, que apresentam altas declividades, porém não possuem grandes espessuras de solos. O modelo não distingue estas áreas e como consequência, as considera como áreas de elevada probabilidade. Devido a esta falta de distinção, pode-se dizer que para um modelo mais preciso, seria necessário analisar estas áreas de afloramentos separadamente, levando em consideração não somente a influência das camadas de solos, mas também realizar uma análise da mecânica das rochas, nas áreas em que se encontram em superfície, uma vez que o Fator de Segurança é utilizado apenas para escorregamentos de solos e não de rochas.

A aplicação do método apresentado refere-se à modelagem da probabilidade de ocorrência de escorregamentos baseando-se somente na análise dos parâmetros físicos do solo o que não exigiu uma análise multitemporal de eventos anteriores de escorregamentos, nem da frequência com que ocorrem. É um método que, aliado a informações de escorregamentos anteriores que auxiliam na validação dos resultados, serve para a prevenção dos eventos, uma vez que através da espacialização dos valores, pode afirmar quais são as áreas mais prováveis de ocorrência de movimentações.

\subsection{Mapa do volume de material suscetível a escorregamentos}

O modelo espacial de probabilidade é representado por cunhas com valores iguais de probabilidade. Essas cunhas transformadas em um shapefile de polígonos, permitiu calcular as diferentes áreas do modelo. Além da área, foram traçadas linhas de comprimento em cada uma das cunhas. Como o modelo gera muitas cunhas de escorregamento, considerando todos os intervalos de probabilidade, foram então separadas somente as que se encontram nos intervalos de 45 a $50 \%$, que seriam as mais suscetíveis à movimentação. Essa forma de modelagem apresentada necessita, dessa forma, que sejam separadas somente as áreas com as quais se deseja trabalhar, na maioria dos casos as de maior probabilidade.

Os valores referentes ao volume de material suscetível a escorregamentos, nas áreas com 45 a 50\% de probabilidade de movimentação, está representado na Figura 9. O mapa distingue as cunhas de escorregamentos por maior volume de material. 


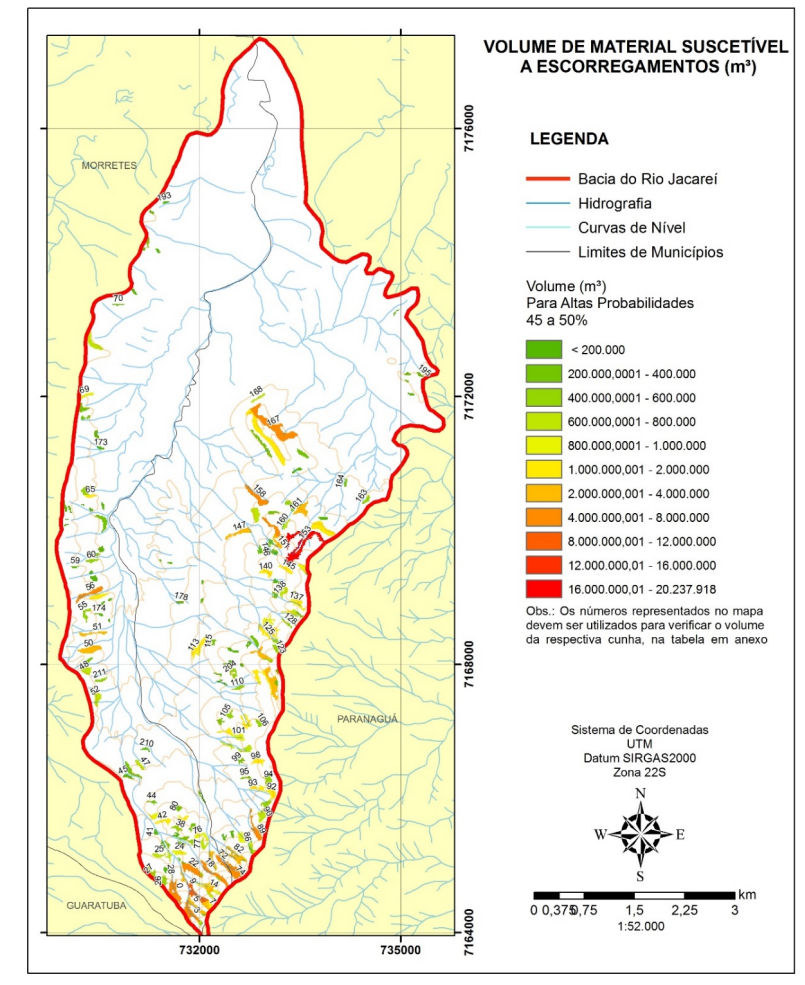

Figura 9 - Mapa do volume de material suscetível a escorregamentos, para as cunhas com muito alta probabilidade (45\% a $50 \%)$.

O volume total de material suscetível a escorregamentos na bacia do rio Jacareí, para as áreas com alta probabilidade, de 45 a $50 \%$, é de $204.940 .481 \mathrm{~m}^{3}$. Este foi determinado somando-se os volumes calculados para cada cunha. O mapa de quantificação do volume é representado em intervalos, porém cada cunha possui um valor exato, que pode ser apresentado em planilhas junto ao modelo.

\section{Conclusão}

A representação espacial do método proposto por Fiori \& Carmignani (2009), para o cálculo da probabilidade com base na análise do equilíbrio limite, foi adequada na identificação e -estimativa de escorregamentos, tanto para áreas com elevadas probabilidades, nas partes mais declivosas e elevadas da bacia, quanto para as áreas com baixas probabilidades ou nulas, que se encontram em sua grande parte nas planícies.

Comparado com as cicatrizes dos escorregamentos de 11 de março de 2011, o modelo apresentou resultados satisfatórios, pois todas as áreas com probabilidades diferentes de 0 englobam as cunhas das cicatrizes em $99 \%$ dos casos observados.

Mesmo com resultados satisfatórios, para que o modelo seja mais preciso nos valores de probabilidade e consequentemente, no volume de material, é importante que exista uma boa malha de amostragem dos diversos tipos de solos, uma vez que o trabalho se baseia exclusivamente nos parâmetros físicos do solo.

De acordo com a metodologia, a tentativa de representar os valores quantitativos de probabilidade e de quantificação do volume de material suscetível a escorregamentos, em forma de modelos espaciais, se mostrou possível. Além disso, torna-se uma ferramenta eficaz para a análise de outras áreas que apresentam os mesmos problemas, ou áreas que não possuem histórico, porém que apresentam características físicas similares.

\section{Agradecimentos}

Esse estudo foi apoiado pela Coordenação de Aperfeiçoamento de Pessoal de Nível Superior como agência de fomento e o CESEC/LACTEC e NUGEO UFPR pelo empréstimo das estruturas laboratoriais.

\section{Referências bibliográficas}

BEVEN, K.J.; KIRKBY, M.J. 1979. A physically based, variable contributing area model of basin hydrology - Un modèle à base physique de zone d'appel variable de l'hydrologie du bassin versant. Hydrological Sciences Bulletin, 24:43-69.

EMBRAPA - Empresa Brasileira de Pesquisa Agropecuária. 2006. Sistema Brasileiro de Classificação de Solos. 2 ed., EMBRAPASPI, Rio de Janeiro, 306p.

FENDRICH, R.; FERREIRA, M.A. 1995. Rosa de frequência dos ventos no Estado do Paraná. Revista Acadêmica da PUC/PR, $11: 49-57$.

FIANI, M.; FAZIO, C.; BARBARELLA, M. 2000. Evaluation of landslide volume using photogrammetric techniques. International Archives of Photogrammetry and Remote Sensing, 33:278-282.

FIORI, A.P.; CARMIGNANI, L. 2009. Fundamentos de mecânica dos solos e das rochas - aplicações na estabilidade de taludes. Editora UFPR, Curitiba, 604p.

KOZCIAK, S. 2005. Análise determinística da estabilidade de vertentes na Bacia do Rio Marumbi - Serra do Mar - Paraná. Tese de Doutorado. Pós-Graduação em Geologia, Departamento de Geologia, Universidade Federal do Paraná, 140p.

SILVEIRA, C.T. 2010. Análise digital do relevo na predição de unidades preliminares de mapeamento de solos: integração de atributos topográficos em Sistemas de Informações Geográficas e Redes Neurais Artificiais. Tese de Doutorado. Pós-Graduação em Geografia, Departamento de Geografia, Universidade Federal do Paraná, 152p.

SILVEIRA, C.T.; FIORI, A.P.; FERREIRA, A.M.; FELIPE, R.S.; KEPEL FILHO, J.L.; FOLADOR, R.M.; COSTA, L.C. 2012. Análise do Fator de Segurança da estabilidade das vertentes na Bacia do Rio Jacareí, Serra do Mar paranaense. Revista Brasileira de Geomorfologia, 13:287-297.

SPIEGEL, M.R. 1977. Estatística: resumo da teoria, 875 problemas resolvidos, 619 problemas propostos. McGraw-Hill do Brasil.

TSUTSUI, K.; ROKUGAWA, S.; NAKAGAWA, H.; MIYAZAKI, S.; CHIN-TUNG, C.; SHIRAISHI, T.; SHIUN-DER, Y. 2007. Detection and volume estimation of large - scale landslides based on elevation - change analysis using DEMs extracted from high - resolution satellite stereo image. IEEE Transactions on Geoscience and Remote Sensing, 45:1681-1696.

WU, T.H.; MCKINNELL III, W.P.; SWANSTON, D.N. 1979. Strenght of tree roots and landslides on Prince of Wales Island, Alaska. Canadian Geotechnical Journal, 16:19-33.

Manuscrito ID 50642

Submetido em fevereiro de 2017 Aceito em fevereiro de 2018 